\section{UNDERSTANDING THE FORMATION OF CARBONATES ON MARS: EXPERIMENTAL APPROACH}

\author{
CAROLINA GIL-LOZANO ${ }^{1,2}$, FABIEN BARON ${ }^{3}$, ANNE \\ GAUDIN $^{1}$, JEAN-PIERRE LORAND ${ }^{1}$, VINCENT \\ FERNANDEZ $^{4}$, JONATHAN HAMON ${ }^{4}$ AND NICOLAS \\ MANGOLD $^{1}$
}

${ }^{1}$ LPG UMR 6112 CNRS/Université de Nantes

${ }^{2}$ Departamento de Geociencas, Universidade de Vigo ${ }^{3}$ IC2MP UMR 7285/Université de Poitiers

${ }^{4}$ Institut des Matériaux Jean Rouxel (IMN), CNRS/Université de Nantes

Presenting Author: carolina.gillozano@univ-nantes.fr

The identification of carbonates on Mars aroused great interest because they have important implications to understand the climatic evolution of the planet and they are indicators of habitable (paleo) environments (i.e., neutral-alkaline $\mathrm{pH}$ aqueous conditions). Regardless of the thicker $\mathrm{CO}_{2}$-rich martian atmosphere during the early history of the planet, carbonates are not as widespread as other secondary minerals (e.g., phyllosilicates, chlorides, or sulfates). A common aspect of many carbonate deposits across the planet is their association with olivine-rich ( $>20 \%$ in volume) rocks [1]. The Nili Fossae region and Jezero crater are beautiful examples of this association where both hydrothermal and surface weathering processes have been claimed [2,3].

In this work, we investigate the formation of carbonates resulting from the aqueous alteration of various Mars analogs samples (including individual silicates and martian crust simulants) under an anoxic $\mathrm{CO}_{2}$-rich atmosphere and warm conditions $\left(\mathrm{PCO}_{2}=1 \mathrm{~atm}, \mathrm{~T}=45^{\circ} \mathrm{C}\right)$. The full experimental details can be found in Baron et al.[4]. The formation of carbonates is classically favored by the dissolution of mafic silicates, because they can neutralize the acidity derived from a $\mathrm{CO}_{2}$-rich atmosphere. Our experimental solutions show that this neutralization was particularly effective in forsterite samples $(\mathrm{pH}=6.4)$ where the XPS spectra showed the formation of carbonates (Fig.1a). However, in crust simulants with more felsic composition $(\mathrm{pH}=5)$ carbonates were no longer formed (Fig.1b).

These results are in line with the mineral association of carbonates and olivine-rich substrate observed on the surface of Mars, highlighting the importance of the host rock composition on the distribution of these minerals. As olivine is not a major component of the Martian crust[5], we extrapolate from our results that the limited extent of carbonates on Mars is mainly related to the lack of olivine, or its low abundance, and that the lack of carbonates cannot be used against a warmer, wetter period in Early Mars for this reason.

\section{References}

[1]Wray et al. (2016), J.Geophys.Res.Planets 121, 652-677.

[2]Ehlmann et al. (2008), Science 322, 1828-1832.

[3]Gaudin et al. (2011). Icarus 216, 257-268.
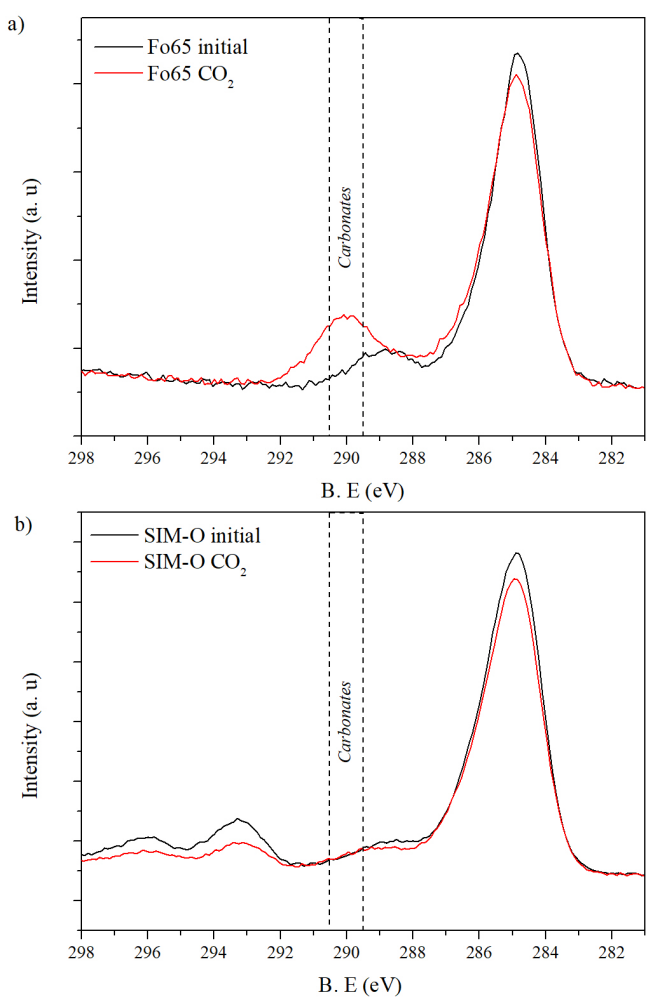

Figure 1. C1s spectra of (a) Individual forsterite (Fo65) samples and (b) Mars crust simulants (Fo65 $<11.8$ wt.\%) before and after aqueous weathering under $\mathrm{CO}_{2}$-rich anoxic atmosphere. 